\title{
BIOCHEMICAL GENETICS OF RESISTANCE AND CROSS RESISTANCE OF Spodoptera littoralis CHECKE (Boisd.) PROGNEY TO CHLORPYRIFOS USING DEVELOPED REARING TECHNIQUE Mohanna, A.H. and H.M. EI-Sharkawy Dept. of plant production ,Faculty of Technology \& Development, Zagazig Uni., Egypt
}

\begin{abstract}
In laboratory tests, a unique technique was carried out to distinguish and obtain developed strains originated from separately reared Spodoptera littoralis (Boisd.) egg- masses ( field and laboratory strains); traditional susceptible strain (Tss) from laboratory strain, and traditional resistant strain ( Trs). from field. Two other strains were obtained in laboratory; the first developed traditional susceptible strain ( dTss.) was originated from the high susceptible larvae of Tss, and was subjected to relaxation for four successive generations. while the second, developed traditional resistant strain( dTrs.) was resulted from moderately to high level larvae of Trs, and was subjected to selection pressure with chlorpyrifos as a selected agent for four successive generations, at the $\mathrm{LC}_{50}$ level. The obtained results revealed that $\mathrm{LC}_{50}$ value of Tss. and dTss. were 0.905 and 0.607 , respectively. Also dTrs. strain was exhibited 14.47 fold of resistance as compared to 8.45 fold for Trs. Strain.

Cross resistance spectrum was tested on dTss, Tss,, UTss .parent, Trs, and dTrs. Using 3 OP's compounds, one carbamate, 2 synthetic pyrethroids, and one demeloid.

All strains tested proved that increase in resistance level was accompanied by steady increase in cross resistance of all tested compounds. All strains tested were in between vigor tolerance to true resistance ( positive cross resistance).Analysis of data showed that developed resistance strain exhibited a moderate level of resistance to the selected agent (chlorpyrifos).

Degree of dominance of resistance in $F_{1} a\left(d T s s\right.$ males $\times$ dTrs females) and $F_{2} b$ (dTrs males $\times$ dTss females) exhibited a moderate level of recessive. Reciprocal crosses in $F_{1}$ progney indicated that increase in $L_{50}$ and slope in $F_{2} b$ ( heterozygous) was done.

Enzyme activity of acid phosphatase (Acph) and alkakine phosphatase ( Alkph) and transaminases enzyme were established for all strains. Generally, it was obvious that chlorpyrifos resistance in S.littoralis expressed as a high activity of enzyme was more exhibited in the developed and hybrid strains, while traditional strains recorded a fluctuated slightly levels.

Keywords: Spodoptera littoralis, Resistance, Susceptible, Enzyme
\end{abstract}

\section{INTRODUCTION}

Resistance is a simple mechanisms that can be attributed to a singular mode of action of a pesticide, which disrupts only one genetically controlled process in the populations appear suddenly, either by selection of resistant individuals in populations or by a mutation, which appear to be the less common of the two means. Furthermore, populations of several insect pests 
now have such a high proportion of individuals resistant to all known insecticides,( Ware ,1982). Resistance is a genetic change in response to selection by toxicants that may impair control in the field (Sparks et al. 1989). As already emphasized, exaggerating the differences between resistant and susceptible individuals improves the resolution between genotypes, (Devonshire et al. 1986).

The frequencies of resistance alleles to each insecticide must be low. These individuals surviving on insecticide are likely to be killed by the other. This assumes that resistant genotype have supstatically lower fitness than the susceptible one. Therefore, their frequency declines during those generations between application of the compound. ( Georghiou et al. 1980). Selection for resistance can occur if a small populations able to survive treatment with insecticides can reproduce and path on their resistance to offspring ( FAO, 2012 ) and Xin- Ju and Hui-Min 2012 ). There is a relationships between the increase of insecticide resistance and the activity of detoxification enzymes. ( Rupa et al 2010). The analysis of reciprocal genetic crosses between resistant Helicoverpa armigera (Hübner) and the susceptible strain showed a semi dominance resistant( Huiru Yan et al. 2012), Glutathion S transferases ( GSTs) play an important role in protecting organisms against the toxicity of reactive oxigenspecies (ROS). Glutathion $s$ transferase enzymes activity was increased in treated larvae, this enzymes plays a role in detoxification mechanism. Therefore this study aimed to investigate the biochemical genetics of resistance and cross resistance of spodoptera littoralis (boisd.) progney to chlorpyrifos using developed rearing technique.

\section{MATERIALS AND METHODS}

Two strains were used in this study, parent ( field) strain which was collected from Kaliobeya, Egypt, during two seasons of 2013,2014 of cotton growing and laboratory strain , supplied by Central Laboratory of Pesticides (C.L.P.), Research Center of Agricultural, Giza, Egypt. Developed technique, based on some egg masses in a completely fitness in each shape and size were chosen by eye fitted from the production of each of two parent strains. Each egg mass was reared alone in a separate container (jar) labeled with a mean number. A portion of 50 larvae of $4^{\text {th }}$ instar larvae from each separate colony were treated by $\mathrm{LC}_{50}$ concentration with the selected agent ( chlorpyrifos) at level of $50 \%$ mortality obtained from parent strain Ldp- line. All egg- masses which exhibited low mortality (20\%) were collected together to become a base line of resistant strain which generated from field strain. On the contrary, for laboratory strain( $80 \%$ death). The technique based on Mohanna ( 1998 a \& b ), that used to conducted a sufficient number of pairs $(\delta$ and $q$ ) of fit moths from first generation after the first technique was carried out. Each pairs ( $\hat{\sigma}$ and $q$ ) in a separate lantern glass was left to copulate, each of them were labeled for stress. The same technique was also carried out on a fit egg mass of strain which exhibited a moderate to high 
level of susceptibility were taken to accomplish to the target of this investigation.

Strains:

1-Laboratory strain, traditional susceptible strain ( Tss.) from Central Laboratory of Pesticides.

2- Untreated traditional susceptible strain (UTss.), of number 1 in relaxation for 4 generations.

3- Developed traditional susceptible strain (dTss.), resulted from laboratory strain after developing technique for four generations.

4- Parent strain (original), Kaliobeya field strain.

5- Traditional resistant strain ( Trs.), parent after selection for 4 successive generations.

6- Developed traditional resistant strain dTrs, originated from parent strain after concentrating the resistant individuals and subjected to selection pressure for 4 successive generations.

\section{Rearing Program:}

Rearing program used to those mentioned by El- Defrawi et al. (1964).

All strains were reared in a room conditions $\left(25 \mathrm{C}^{\circ} \pm 5 \%\right.$ and $\left.65 \pm 5 \% \mathrm{RH}\right)$ with continuous cleanup in all steps.

Insecticides:

Three organophosphate compounds [profenfos, chlopyrifos,(selected agent) and cyanofos], two synthetic pyrethroids namely, fenvalerate, and decamethrin, and a carbamate methomyl, besides to the demeloid diflubenzuron, were used in this study.

Toxicological STUDIES:

Treated strains of Spodoptera littoralis (Boid.), were subjected to chemical selections with chlorpyrifos for four successive generations. Selection was carried out on $4^{\text {th }}$ instar larvae at a level of LC $_{50}$.

\section{Cross RESISTANCE:}

Cross resistance spectrum to different insecticides was determined at the end of selection in G4 selected generation, on all strains. Mortality data were corrected according to the formula of Abbot (1925). The $\mathrm{LC}_{50}$ and slope values were estimated by method of Busvine (1957). The rate of development of resistance to chlorpyrifos together with cross resistance ratio were assessed and based on LC $_{50}$ of selected strain compared with their corresponding values of the susceptible strain, dTss.

\section{Genetic ANALYSIS:}

Larvae of dTss and dTrs strains were permitted to pupate, Pupae were differentiated, males and females were kept separately petri dishes placed in cages to prevent uncontrolled mating after emergence. Equal numbers of moths from dTss and dTrs ( 60 males and 60 females), were prepared. Reciprocal crosses were between 25 male from dTss and 25 female dTrs $\left(F_{1} a\right)$ ], besides to [25 males dTrs and 25 female of dTss. $\left(F_{1} b\right)$. A portion of each of two reciprocal $F_{1}$ hybrid was tested to determine $L_{50}$ values. $F_{1}$ hybrid was pooled together and left to give $F_{2}$ progney. $L_{50}$ of $F_{2}$ was established. The degree of dominance (D) of resistance in $F_{1}$ offspring was calculated by Falconer formula (1964) according to Stone (1968). 
Where:

$$
\mathrm{D}-\frac{2 \times L C 50(R S)-\mathrm{LC50}(\mathrm{RR})-\mathrm{LC50}(\mathrm{SS})}{L C 50(R R)--\operatorname{LCS0}(5 S)}
$$

RR, RS, SS, represent resistant, heterozygote, $\left(F_{1}\right)$, and susceptible population, respectively. The $\mathrm{LC}_{50}$ are expressed in terms of their logarithm. The values thus derived indicates whether resistance in fully recessive $(D=-$ 1), intermediate $(D=0)$ and fully dominant $(D=1)$. Other results in between the two extremes indicate partial or incomplete inheritance of character.

Enzyme Assays:

Insensitive enzyme activities were measured for each of six strains. Larvae of $4^{\text {th }}$ instar ( average weight $37-40 \mathrm{mg}$.)were collected for each strain at G4. Larvae of all samples were starved for about $4 \mathrm{hrs}$. before being homogenized in distilled water ( 5 larvae $/ \mathrm{ml}$.). The homogenates were centrifuged for $15 \mathrm{~min}$. at 10.000 r.p.m. at $2 \mathrm{C}^{\circ}$ and supematant fraction was used for enzyme assay. The method described by Pawel and Smith(1954), was used for determination of acid phosphatase, and alkaline phosphatase activity. The procedure was based on the hydrolysis of disodium phenyl phosphate ( substrate) in acid media ( $\mathrm{pH} 4.5)$ for Acp., or ( $\mathrm{pH} 10.5)$ for alkaline media, to yield phenol. Hydrolyzed phenol after reacting with 4 amino antipyrine yield red color, which read spotophotometrically.

Transaminases enzyme activities glutamic oxaloacetic transferase(GOT), and glutamicpyruvic transferase (GPT), were determined according to the method described by Reitman and Frankel(1957), using alpha - keto glutorate / dL- aspartate ( $2 \mathrm{mM} .+200 \mathrm{Mm}$.)and alpha ketoglutarate / dL. Alanine ( $2 \mathrm{Mm}$. $+200 \mathrm{M}$.) as substrates for GOT and GPT, respectively. Enzyme activity was expressed as uM pyruvate / min. / larvae. All colorimetric determinations were based on a minimum of four replications for each sample, and all homogenates were incubated with substrates at $37 \mathrm{C}^{\circ}$ for half an hour.

Enzyme assays in hybrid strains, was done. In these experiments, $4^{\text {th }}$ instar larvae average weight, (40-45 mg.), were collected from each of strains in last generation besides to the samples of $F_{1} a, F_{1} b, F_{2} a$, and $F_{2} b$ of genetic analysis.

\section{RESULTS AND DISCUSSION}

The present work represents a trial to accelerate the susceptibility of any strain either low or high, depending on developed technique of Mohanna ( 1998 a \& b). Susceptibility of $4^{\text {th }}$ instar larvae of Tss. and dTss. Throughout four successive generations without any exposure to insecticide treatments are shown in Table (1). The base line strain Tss, LC 50 was 0.905 , while the susceptibility increased during four generations of relaxation to 0.607 in dTss. with 1.57 fold of susceptibility as compared to dTss On the other hand, the rate of development of resistance to chlorpyrifos on parent (field), $\mathrm{LC}_{50}$ was 1.99 , with 3.28 fold of susceptibility as compared to dTss. With continuous selection to field or parent, resistant ratios in moderate to tolerate led to 8.45 
fold, LC $_{50} 5.13$ at the end of selsction. The strain reatched to 14.47 fold, ( $\mathrm{LC}_{50}, 8.79$ ) when developed technique was carried out in it, after 4 successive generations with selected agent ,.Mohanna and El Sharkawy, (2015)

Table(1):Comparative studies of the development of resistance to chlorpyrifos in 4 th instar larvae of $S$. littoralis in a traditional and developed technique forms.

\begin{tabular}{|l|c|c|c|}
\hline Strain & $\begin{array}{c}\text { Slope } \\
\mathbf{5 \%} \text { fiducial limits }\end{array}$ & $\begin{array}{c}\mathbf{L C}_{\mathbf{5 0}} \\
\mathbf{5 \%} \text { fiducial limits }\end{array}$ & R R \\
\hline dTSS & 2.209 & $0.607(0.480-0.771)$ & -------- \\
\hline uTss & 2.157 & $0.856(0.682-1.140)$ & 1.41 \\
\hline Tss & 2.446 & $0.905(0.718-1.114)$ & 1.57 \\
\hline parent & 2.635 & $1.991(1.572-2.483)$ & 3.28 \\
\hline Trs & 2.301 & $5.128(3.710-6.520)$ & 8.45 \\
\hline dTrs & 2.257 & $8.786(5.868-11.255)$ & 14.47 \\
\hline
\end{tabular}

Cross resistance pattern to several insecticides tested on dTss, uTss, Tss, parent, Trs, and dTrs, strains is presented in Table (2), The standard (developed) susceptible strain, dTss, was remarkably highly susceptible to all tested insecticides. Untreated traditional susceptible strain UTss,was exhibited slightly effect on $S$. littoralis , $4^{\text {th }}$ instar larvae against all tested compounds. Poorly effects are also observed on traditional susceptible strain, when tested with the same compounds. Regarding to parent strain which exhibited a low level of tolerance to cyanofos, $(R R=2.49$ fold $)$, and chlorpyrifos (3.28 fold) followed by diflubenzuron with 4.17 fold .The carbamate methomyl and diflubenzuron recorded 6.28 and 4.17 fold of tolerance as compared to dTss. The profenfos came the next with 7.35 fold of vigor tolerance.

On the other hand, the pyrethroid fenvalerate was more resistant than the selective agent with 25.57 fold of resistance.

Traditional resistant strain Trs which was selected with chlorpyrifos for four successive generations and experimented to cross resistance agents were exhibited a slight level of tolerance to the cyanofos with 5.34 fold, followed by diflubenzuron, 7.69 fold, while methomyl recorded 9.34 fold of resistance at the end of selection in G4. Truly cross resistance was clear when used synthetic pyrethroids decamethrin which recorded 12.84 fold, while the poorly fenvalerate exhibited clear resistant ratio 71.43 fold as compared with dTss. The developed resistant strain dTrs for chlorpyrifos manifested a high level of resistance to each of fenvalerate 284.74 fold and diflubenzuron 28.19 fold followed by profenfos 27.21 fold, but decamethrin came the next with 26.05 fold of resistance. Positive resistance was recorded by cyanofos, 19.83 fold, followed by methomyl, which recorded 19.19 fold of resistance on chlorpyrifos selected strain (14.47 fold) at the end of selection in G4 as compared to dTss. 
Mohanna, A.H. and H.M. El-Sharkawy. 
Those findings agreed either totally or partially with results of Georghiou and Calmen ( 1969), and Cert \& Georghiou(1974), indicating that resistance to organophosphate compounds and organochlorines, also possess high level of cross resistance to insect growth regulator. Also agree with findings of ElSayed et al. (1982- 1983), indicating certain level of resistance established before the selected strain is ready to coffer cross resistance to other insecticides and that the level of cross resistance increased with progressive selection. Mohanna and Hossain (1999)and Moshtaq et al. (2007), Generally level of resistance were very low to endosulfon, chlorpyrifos, phoxim, quinalphos, profenfos, bifenthrin, and thiocarb, and a moderate to high level to methomyl and cyfluthrin. Correlation analysis indicated that insecticides belonging to the same class such as in S. littoralis . Positive correlation was also found between endosulfon and carbamate, Adel and Freed (2014); and Ghasem et al.(2015).

Data of the degree of dominance for resistance are shown in Table(3). It is cleared that $F_{1} a$ (dTss males $\times$ dTrs females ) and $F_{1} b$ (dTrs males $\times$ dTss females), exhibited a high recessive degree $(D=-0.79)$ and ( $D=-0.84$ ), respectively. Resistant ratio of $F_{1}$ aand $F_{1} b$ were 6.35 and 6.02 folds. Slightly decreases in slope values from 2.373 to 2.247 accompanied with decreasing $\mathrm{LC}_{50}$ value from 3.857 to 3.653 , means that the strain being slightly heterozygous. On the other hand, $\mathrm{F}_{2} \mathrm{~b}$ was exhibited an increased in the slope of Ldp- line from 2.226 to 3.446 and decreased in $\mathrm{LC}_{50}$ from 5.4507 to 4.9407 , that refers to more heterozygosity in the individuals of this generation .These data agree with Hoskins and Gordon (1956)and Rossi \& Prescutti (1996), they mentioned that crosses between unselected and selected strains of Piophila cosei (L.),were done. Results of survival analysis in $F_{1}$ hybrids were analogous for males and females and were similar in both reciprocal crosses. $\mathrm{LC}_{50}$ 's for deltamethrin were intermediate between those of the parental strains. Similarly, several authors arrived almost to the same findings; Head et al.(1995), Gunning et al. (1995); Argentine et al. (1995); Thomas and Boethal (1995); Rupa et al.(2010), the analysis of reciprocal genetic crosses between resistant Helecoverpa armigera strain ( 227.9 fold), and susceptible strain showed dominance $(D=0.299-0.782)$, suggesting Cryl Ac resistance as a semi - dominance trait. Also agree with Muhammed et al. (2015).

Either acid phosphatase ( Acp) or alkaline phosphatase (Alkp) activities were fluctuated between strains summarized in Table (4);, Regarding to Acp which inhibited by Tss and uTss, recording -30.12 and $-28.29 \%$ activity as compared to dTss. Parent strain exhibited high level of activity $(25.30 \%$, followed by Trs which was exhibited a moderate level of ( $79.51 \%)$ activity. On the other hand, developed traditional resistant strain was the top of activities with $306.02 \%$, and $\mathrm{F}_{2}$ a hybrid strain came the next with $249.4 \%$ activity as compared to the standard strain (dTss.).Strains which generated from hybrids recorded a moderately level of 13.73 , and $116.87 \%$ activity for dTss and dTrs respectively. Similarly results were obtained from Alkp., when experimented on dTrs, recorded the highest level of activity,( $196.83 \%)$, accompanied by $\mathrm{F}_{2} \mathrm{a}$ hybrid strain with $(188.47 \%)$, and $\mathrm{F}_{2} \mathrm{~b}$ recorded 
( $184.44 \%$ ), but $F_{1} b$ come in the latent effect of this group with (165.42\%). The second category of activity was $\mathrm{F}_{1} \mathrm{a}$,Trs, and parent strains; $150.72,134$ and $97.69 \%$ activities. Low level of activity was recorded by uTss. $12.97 \%$. The monostatic which exhibited a moderate level of inhibition was Tss recorded $-38.90 \%$ activity for alkaline phosphate, as compared to dTss.. The present results are in agreement with those of, Van Asperen (1960) Abdallah et al. (1973); Hassan (1979);Abd Elsamie et al. (1979) ); Gomaa et al. (1982),Abdel Hafez et al. (1993) Mohanna\&Hossain(1999) and Muhammed et al. (2015).

Table (3): $F_{1}$ generation generated from reciprocal crosses between dTss and dTrs, strains, and $F_{2}$ derives from pooled $F_{1}$ hybrids using chlorpyrifos in $4^{\text {th }}$ instar larvae of S. littoralis.

\begin{tabular}{|c|c|c|c|c|}
\hline Hybrid strains & Slope & LC $_{50}$ ( $5 \%$ fiducial limits) & $\begin{array}{l}\text { Degree of } \\
\text { dominance }\end{array}$ & RR \\
\hline $\begin{array}{l}\mathrm{F}_{1} \mathrm{a}(\mathrm{dTss} \\
\text { females) }\end{array}$ & 2.373 & $\begin{array}{c}3.8570 \\
(3.0786-4.8469)\end{array}$ & $0.79-$ & 6.35 \\
\hline $\begin{array}{l}\mathrm{F}_{1} \mathrm{~b} \text { (dTrs malex } \mathrm{dTss} \\
\text { female) }\end{array}$ & 2.247 & $\begin{array}{c}3.6529 \\
(2.4830-4.5637)\end{array}$ & $0.84-$ & 6.02 \\
\hline F2a,(reciprocal crosses ) & 2.266 & $\begin{array}{c}5.4507 \\
(4.3675-6.9666)\end{array}$ & --- & 8.98 \\
\hline F2b,(reciprocal crosses ) & 3.446 & $\begin{array}{c}4.9407 \\
(4.1327-5.9163)\end{array}$ & --- & 8.15 \\
\hline
\end{tabular}

Table (4): Activity of Acp., Alkp., and (GOT\&GPT) transaminases enzyme in $4^{\text {th }}$ instar larvae of S.littoralis for different strains developed by certain technique, and having different level of susceptibility to chlorpyrifos, besides to strains resulting from hybrids.

\begin{tabular}{|c|c|c|c|c|c|c|c|c|c|c|}
\hline \multirow{2}{*}{ Strain } & \multirow{2}{*}{\multicolumn{2}{|c|}{ Slope $L_{50}$}} & \multicolumn{4}{|c|}{ Acid phosphatase Alkalinephosphatase } & \multicolumn{2}{|c|}{ GOT } & \multicolumn{2}{|c|}{ GPT } \\
\hline & & & Acp & $\%$ & alkp & $\%$ & GOT & $\%$ & GPT & $\%$ \\
\hline dTss & 2.22 & 0.607 & 1.66 & & 3.47 & ---------- & 10.73 & & 0.19 & \\
\hline UTss & 231 & 0.056 & 1.18 & $28.29-$ & 3.92 & 12.97 & 9.88 & 7.92 & 0.16 & $15.75-$ \\
\hline tss & 2.45 & 0.905 & 1.16 & -30.12 & 2.12 & -38.90 & 10.97 & 2.24 & 0.13 & -31.58 \\
\hline Parent & 2.64 & 1.991 & 2.08 & 25.30 & 6.68 & 97.69 & 10.44 & -2.27 & 0.28 & 47.37 \\
\hline \begin{tabular}{|l|l} 
Trs \\
\end{tabular} & 2.30 & 5.128 & 2.98 & 79.51 & 8.12 & 134 & 13.07 & 21.81 & 0.31 & 63.16 \\
\hline dTrs & 2.26 & 8.786 & 6.74 & 306.02 & 10.30 & 196.83 & 13.91 & 29.64 & 0.36 & 89.47 \\
\hline $\mathrm{F}_{1} \mathrm{a}$ & 2.32 & 3.857 & 3.60 & 116.87 & 8.70 & 150.72 & 12.11 & 12.86 & 0.33 & 73.68 \\
\hline$F_{1} b$ & 2.25 & 3.653 & 3.88 & 133.73 & 9.21 & 165.42 & 13.06 & 21.71 & 0.44 & 131.58 \\
\hline $\mathrm{F}_{2} \mathrm{a}$ & 2.27 & 5.451 & 5.80 & 249.40 & 10.01 & 188.47 & 12.97 & 20.88 & 0.31 & 63.15 \\
\hline $\mathrm{F}_{2} \mathrm{~b}$ & 3.45 & 4.978 & 6.12 & 268.67 & 9.87 & 184.44 & 14.36 & 33.83 & 0.37 & 94.74 \\
\hline
\end{tabular}

Regarding, transaminases enzyme, data in Table (4) also proved that uTss, and parent strain inhibited GOT with -7.92 and $-2.27 \%$,respectively. Whereas, uTss, and Tss strains were in the same behavior GPT with -15.75 and31.58 \%. High low to low activity to GOT were recorded in Tss, Trs, $\mathrm{F}_{1}$ a and $\mathrm{F}_{2} \mathrm{a}$, ranged between 2.24 to $21.81 \%$ activity .Moderate level of activity was recorded by $\mathrm{F}_{2} \mathrm{~b}$ with $33.83 \%$ as compared to dTss. Glutamic pyruvic transferase inhibition was clear in UTss, and Tss, recording - 15.75 and - 
$31.58 \%$ inhibition respectively. The hybrid $F_{1} b$ was the highest activity , recorded $131.58 \%$ activity, followed by $\mathrm{F}_{2} \mathrm{~b}$ with $94.74 \%$, while dTrs came the next with $89.47 \%$ activity. The third category which included $F_{1} a$, Trs, and $\mathrm{F}_{2} \mathrm{~b}$ recorded $73.68,63.16$, and $94.74 \%$ activity. Parent strain was recorded $47.37 \%$ activity as compared to dTss. In other word, increases of enzyme activities were clearly observed in strains developed by modified techniques and hybrids than strains developed by traditional once. Similar results with modified techniques are also recorded by Shaaban et al.(19781979)and Mohanna (1998 a\&b), where they mentioned that Ch-E and acid phosphatase in $S$. littoralis seem to play a considerable role in resistance to OP's insecticides, Shoji and Hisaak (2005), glutathione s transferase, play an important role in protecting organisms against the toxicity of reactive oxygen species (ROS).Gllutathion $s$ transferase enzyme activity was increased in treated larvae, this enzyme play a role in detoxification mechanism in insects, therefore may be an over production of this enzymes occurred as a result of treated .Sarita et al. (2010), Wang et al. (2010) and Ghasm et al.(2015)who a reported that glutathione s transferase was a higher in treated larvae than in untreated one.

\section{REFERANCES}

Abbott, W. S. (1925): A method of computing the effectiveness of an insecticide. J. Econ. Entomol. 18: 265- 267.

Abd El Sammie, M. B.; H.M.Salem, and M. Mohie (1979): Identification and distribution of esterases and phosphatases isozymes in various tissues of susceptible and resistat strains to insecticides of cotton leafwor Spodoptera littoralis (Boisd.). Proc. 3rd. Arab Pesticide Conf., Tata Univ., 540

Abdallah, M. D.; M.H. Zaazou; A. M. Ali and M. R. Riskallah (1973) : Cholinesterase and aliesterase activity at different stages in the life cycle of organophosphorus resistant and susceptible Spodoptera littoralis (Boisd.). Bull. Ent.Soc. Egypt Econ. Ser.7:229- 234.

Abdel Hafez, M. M.; A. M. Abdel Kawy; A. H. Mohanna; and M. H. El Bishry (1993): Effect of IGR / insecticides mixtures on carbohydrate hydrolyzing enzymes of Spodoptera littoralis (Boisd.) larvae. J. Produc. \& Deve.1(2): 165- 177.

Adel Rehan, Shoab Freed (2014): Resistance selection mechanism and stability of S. littoralis (Boisd.) (Lipidoptera: Noctuidae ) to methomyl fenozide.Pesti. Biochem. And Physiol.Vol.110;pp.7-12.

Argentine, J. A.; S. H. Lee; M. A. Sos; S. R. Berry and J. M. Clarr (1995): Permithrin resistance in a near isogenic strain of Potato Beetle. Pest. Biochem. And Physiol. :53;97-115.

Busvine, J. R. (1957); A critical review of the technique for testing insecticides.Commonwealth Inset. Entomol. London p., 167- 184.

Cert D. C. and G. P. GeOrghiou (1974): Cross resistance to an inhibitor of chitin synthesis, TH60- 40, in insecticide resistance strains of the house fly . J. Agr. Food Chem., 22: 1145- 1146. 
Devonshire, A. L.; G. D. Moores and R. H. French - Constant (1986):Detection of insecticide resistance of immunological estimation of e)antiserum with Pharodon humuli (Schrank) (Hemiptera ; Aphididae ). Bull Enonntomol. Res. 76: 97- 107.

El- Sayed, E. I. ; A. H. Mohanna and M. M. Abdel Sattar (1982- 1983) : Pattern of cross resistance in endrin and methomyl selected selected strains of the Egyption cotton leafworm Spodoptera littoralis (Boisd.) Bull. Ento. Soc. Egypt, Econ.Ser, 13: 17-24.

El-Defrawi, M. E. ; A. Toppozada; A. Salama and S. A. El-Kheshen (1964): Toxicological studies on Egyption cotton leafworm, Prodenia litura (F.): Revision of toxaphene resistance in Egyption cotton leafworm.J. Econ. Entomol., 57: 593- 595.

Falconer,D. S. (1964) : Introduction to quantitative genetics. The Ronald press Company, New York, 356 pp.

FOA,(2012): Guidelines on Prevention and Management of Pesticide resistance. Copyright @ faw. Org. or to the Chief, Publishing Policy and Support Branch,office of Knowldge Exchange, Research and extention, FAW ,Viale Delle Terme di Caracall,00153 Room, Italy.

Georghiou, G. P.; and J. R. Calmen (1969): Results of fenitrothion selection Culex pipiens fatigans and Anophilus albimonus Bull.W ID HLTH. ORG: 40: 97- 101.

Georghiou, G. P.; N. Pasteur and M. K. Howly (1980): Linkage relationship between organophosphate resistance and highly active esterase- $\beta$ in Culex quinquefasciatus from California, J. Econ Entomol. 73: 301- 305.

Ghasem, A. S., Mir J. ,Hejazi, J. ,Scott F., Mohammed - Reza Rashidi (2015): Selection for chlorpyrifos in Liriomyza sativae (Blanchard.): cross resistance patterns stability and biochemical mechanisms. Pesi. Bioch. and Physiol.Vol. 124 :315-323.

Gomaa, E. A. ;M. A. El Tantawy and A. A. Kdidr (1982): Esterase activity in different stages of the American bollworm, Heliothes zea Proc.2 nd. Egyptian Hungarien Conf. Plant Protection:53-62.

Gunning,R. V. ; G. D. Moores and A. L. Devonshire (1995): Esterases and esfenvalerate resistance in Australian Helioverpa armigera (Hubber.) (Lepidoptera: Noctuidae) Pestic. Biochem. And Physiol., 54:12-23.

Hassan, A. M. (1979): Biochemical studies on the action of some insecticides . M. Sc. Thesis Al Azhar Univer. Pp, 81.

Head, G. ; C. W. Hoy and F. R. Hall (1995): Quantitive genetics of behavioral and physiological response to permethrin in diamond back moth (Lipidoptera: Plutellidae) J. Econ. Entomol., 88 (34) 461- 469.

Hoskins, W. M. and H. T. Gordon (1956): Arthropod resistance to chemicals. Ann. Rev. Entomol., 1: 89-122.

Huiru Y., Fei M., Haihong J., Xing Q. Guo, X. (2012): The identification and oxidative stress response of a zeta class glutathione s- transferase (GSTZ1 ) gene from Apis cerane carina.Journal of Insect Physiology. Vol. 58:782-791.

Mohanna, A. H. (1998a): Differentiation of resistant and susceptible individuals in Spodoptera littoralis (Boisd.) progney and esterases activity. J. Agric. Sci. Mansoura Univ. 23 (4): 1709- 1720. 
Mohanna, A. H. (1998b): Detection of susceptibility in Spodoptera littoralis (Boisd.) progney to cypermethrin in relation to esterases activity. J. Agric. Sci. Mansoura Univ., 23 (8): 3919- 3930.

Mohanna, A. H. ; and A. M. Hossain (1999): Developed techniques for susceptibility classificationin Spodoptera littoralis (Boisd.) Progney in relation to fenitrothion resistance with some biochemical aspects. Minufiya J. Agric. Res. 24 (3): 1107- 1121.

Mohanna, A. H. and El-Sharkawy, H. M.(2015): Genetic Techniques To Evaluate Resistant And Susceptible Individuals Of Spodoptera littoralis (Boisduval) Progney, And Esterases Activityded

Life science journal vol. 12(11):162-167

Moshtaq A., M. Iqbal Aref, Munir Ahmed (2007) :Occurrence of insecticide resistance in field populations of $S$. littoralis (Lepidoptera; Noctuidae) in Pakistan. Crop Production,Vol. 26, pp; 809- 817.

Muhammad Babar Shahzad Afzal, Naeem Abbas, Sarifaz Ali Shad, (2015): Inheritance realized heritability and biochemical mechanism of a cetamiprid resistance in the cotton mealy bug Phenaceccus solenopsis (Tinsleg) ( Hemoptera ; Pseudococcidae ) Pesticide Biochem. and Physiol. ,122:44- 49.

Powell, M. E. A. and M. J. H. Smith (1954): The determination of serum acid and alkaline phosphatases activity with 4-amino- antipyrine. J. Clin.Pathol., 7: 245- 248.

Reitman, S. M. D. and Frankel,S. (1957): A colorimetric method for the determination of serum glutamic oxaloacetic and glutamic pyruvic transaminase.Ann. J. Clin. Pathol.28:56-62.

Rossi, E. and S. Prescuttini (1996) :Development of insecticide resistance in Rophila casei (Diptera : Rophilidae) strains selected with deltamethrin. J. Econ. Entomol. 89 (1): 15-20.

Rupa N., Vinay, K. ,Aggrwal, K. and Govind T. G. (2010): Inhertance of Cry1 Ac resistance and associated biological trails in the cotton bollworm, Helocoverpa armigera (Lepidoptera : Noctuidae) J. Invertibrate Pathology, Vol.(104) pp 31-38.

Sarita, N. ; Moharil, M. P., Ghodki B. S. Lande, G. . K. Bisane, K. Thakare, A. S. Barkhades U. P. (2010): Biochemical analysis and synergistic suppression of indoxicarb resistance in Platella xyleostella L. .J. AsiaPasific Entomol.13 (2), 91- 95.

Shaaban, A. M. ;A. S. Kansouh and A. M. K. Sobeha (1978- 1979): Enzymatic sensitivity in different strains of Spodoptera littoralis (Boisd.) to certain organophosphorus insecticides. Bull. Ento Soc. Egypt Econ. Ser., 11: 11-20.

Shoji Sonoda, Hiasaaki Tsumnki (2005): Studies on glutathione stransferase gene involved in chlofluazuron resistance of diamond back/ Platella xylostella (Lepodoptera: Yponoroeutidae). Pest. Biochem. And Physiol. ,82:pp. 84-101.

Sparkes, T. C.; J. A. Lockwood; R. L. Byford; J. B. Graves and B. R. Leonard(1989): The role of behavior in insecticide resistance. Pesticide Science, 26 (4) 383-399. 
Stone, B. F. (1968): A formula for determining degree of dominance in cases of monofactorial resistance to chemicals. Bull.WHO, 22; 587- 590.

Thomas, J. D. and D. J. Boethel (1995): Inhertance of permethrin resistance in the soyabean hopper (Lepidoptera : Noctuidae). J. Econ. Entomol. 88 (6) 1536- 1541.

Van Asperen, K. (1960): Toxic action of organophosphorus compounds and esterase inhibition in houseflies.Biochem. Pharma. 3: 136-140.

Wang, K. Y., Yang Z., Yan W. H., Ming X. X. and Xiam L. T. (2010): Influence of three diets on susceptibility of selected insecticides and activities of detoxification esterases of Helocoverpa assulto (Lepidoptera: Noctuidae) . Pest. Bioch. Physiol. 96(1), 51-55.

Ware, W. G. (1982): Pesticides theory and application (W. H. Freeman and Company Sanfrancisco, pp.308.

Xin- Ju G. and Hui- Min, S.( 2012) : Resistance with fenpropathrin and the change of detoxification enzyme activities in Tetranychus urticae ( koh)( Acari- Tetranychidae). Acta Entomologica Sinica, 54(1) : 64- 69.

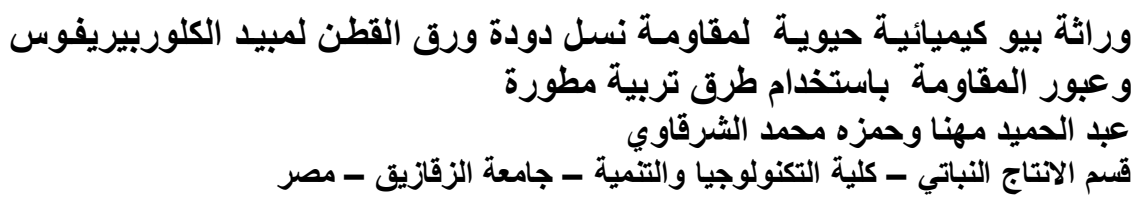

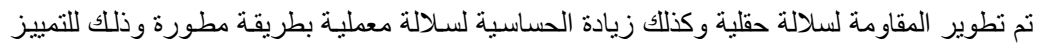

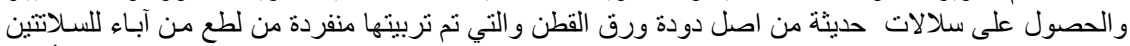

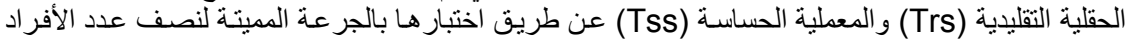

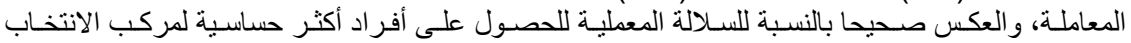

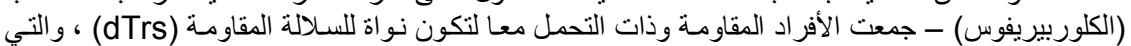

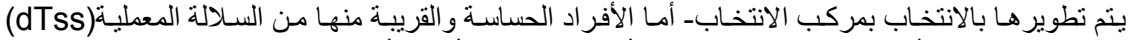

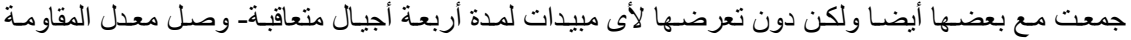

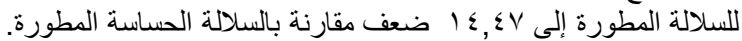

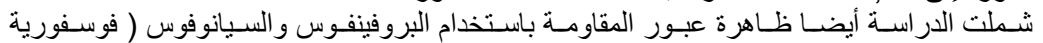

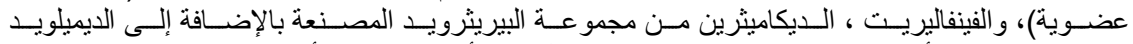

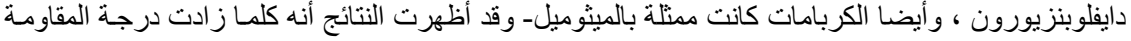

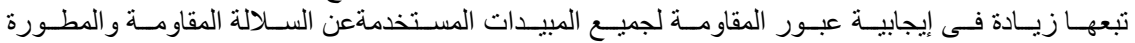

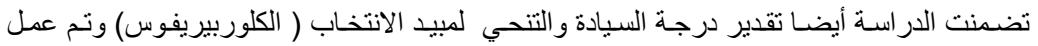
للكلوربيريفوس. تصني

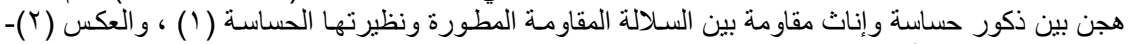

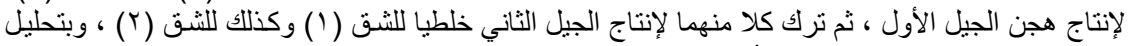

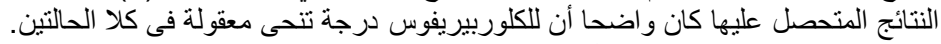

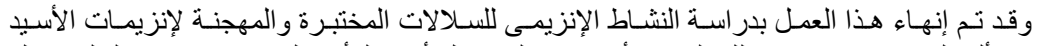

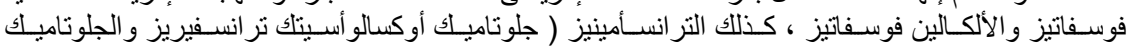

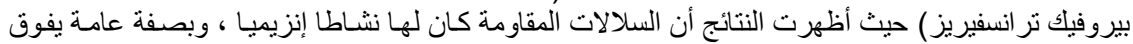

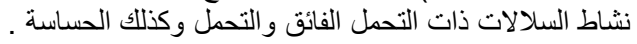


J. Plant Prot. and Path., Mansoura Univ., Vol. 6 (11), November, 2015

1567 



\begin{tabular}{|c|c|c|c|c|c|c|c|c|c|}
\hline$\stackrel{\mathscr{D}}{\bar{\sigma}}$ & & $\frac{\alpha}{\alpha}$ & 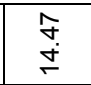 & $\stackrel{\bar{N}}{\stackrel{N}{N}}$ & 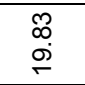 & $\stackrel{\circ}{\circ}$ & 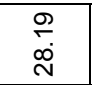 & 等 & $\begin{array}{l}\qquad 0 \\
i \dot{i} \\
\end{array}$ \\
\hline 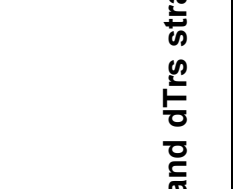 & 농 & 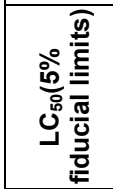 & 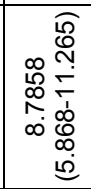 & 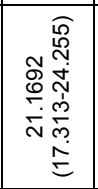 & 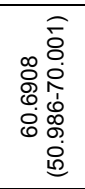 & 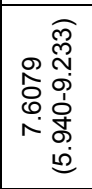 & 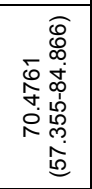 & 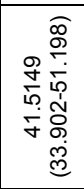 & 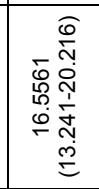 \\
\hline & & $\frac{\Xi}{\omega}$ & $\stackrel{\mathscr{N}}{N}$ & $\stackrel{\mathscr{\Omega}}{\mathrm{N}}$ & $\stackrel{\infty}{\stackrel{\infty}{m}}$ & $\stackrel{\infty}{\stackrel{\infty}{i}}$ & $\stackrel{\bar{m}}{\bar{m}}$ & $\stackrel{\leftrightarrow}{N}$ & $\begin{array}{l}8 \\
\dot{m}\end{array}$ \\
\hline$\stackrel{\overrightarrow{0}}{0}$ & & $\frac{\mathscr{\alpha}}{\alpha}$ & $\begin{array}{l}m \\
q \\
\infty \\
\end{array}$ & $\begin{array}{l}\stackrel{\text { Nิ }}{+} \\
\stackrel{+}{+}\end{array}$ & 总 & 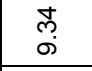 & $\stackrel{8}{\stackrel{8}{\wedge}}$ & $\frac{\text { m}}{\stackrel{N}{\Lambda}}$ & $\begin{array}{l}\stackrel{0}{\infty} \\
\stackrel{\text { }}{\sim}\end{array}$ \\
\hline 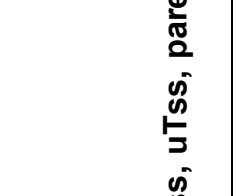 & $\stackrel{n}{=}$ & 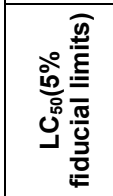 & 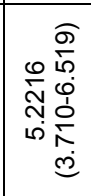 & 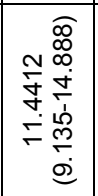 & 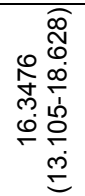 & 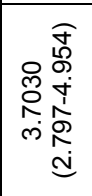 & 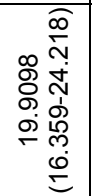 & 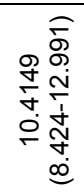 & 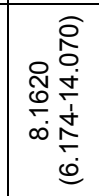 \\
\hline (n) & & $\frac{0}{0}$ & ণ্লি & 芯 & $\begin{array}{l}\infty \\
0 \\
\infty\end{array}$ & 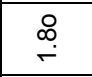 & $\frac{\circ}{\dot{m}}$ & $\stackrel{i}{i}$ & $\stackrel{+}{\text { S }}$ \\
\hline$\stackrel{n}{=}$ & & $\frac{\alpha}{\alpha x}$ & 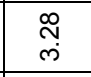 & 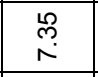 & $\stackrel{g}{i}$ & 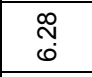 & $\underset{f}{\check{f}}$ & $\begin{array}{l}\text { in } \\
\stackrel{\text { Dे }}{N}\end{array}$ & $\begin{array}{l}\frac{m}{6} \\
\dot{m}\end{array}$ \\
\hline 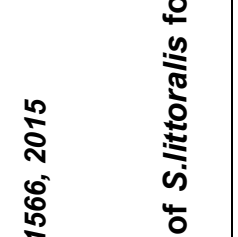 & 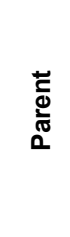 & 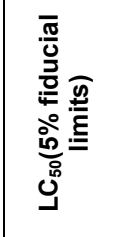 & 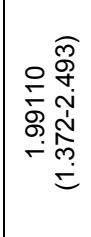 & 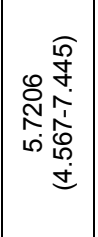 & 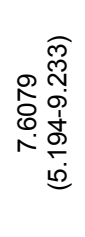 & 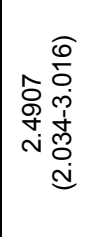 & 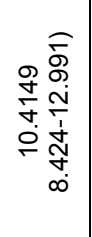 & 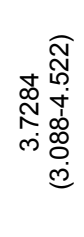 & 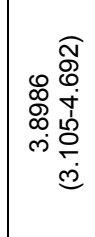 \\
\hline 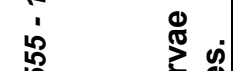 & & $\frac{\frac{0}{0}}{\omega}$ & 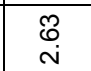 & $\stackrel{\infty}{\stackrel{\leftrightarrow}{N}}$ & $\stackrel{\infty}{\stackrel{⿰}{N}}$ & $\stackrel{\infty}{\infty}$ & $\underset{\text { S }}{\text { S }}$ & $\stackrel{\widehat{\infty}}{\stackrel{N}{N}}$ & $\stackrel{10}{\stackrel{m}{m}}$ \\
\hline$\frac{\pi}{0} .0$ & & $\frac{\alpha}{\alpha x}$ & $\underset{+}{+}$ & 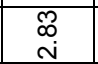 & $\stackrel{m}{\rightleftarrows}$ & $\stackrel{\grave{i}}{i}$ & $\stackrel{\infty}{\stackrel{\infty}{\leftarrow}}$ & $\begin{array}{l}\stackrel{0}{\infty} \\
\stackrel{+}{+}\end{array}$ & $\stackrel{\frac{10}{i}}{\mathbf{N}}$ \\
\hline 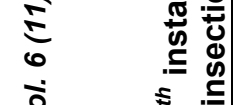 & 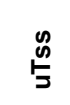 & & 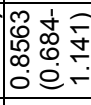 & 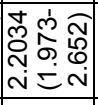 & 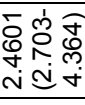 & 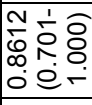 & 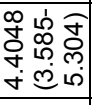 & 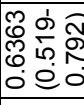 & 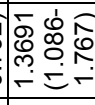 \\
\hline 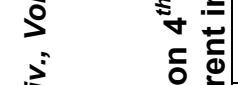 & & $\frac{0}{0}$ & $\stackrel{0}{\grave{i}}$ & $\underset{\dot{m}}{\bar{m}}$ & $\stackrel{\text { N }}{\text { N }}$ & 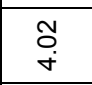 & $\stackrel{F}{\dot{m}}$ & S & $\begin{array}{l}\stackrel{R}{R} \\
\stackrel{N}{N}\end{array}$ \\
\hline 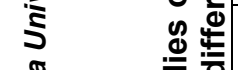 & & $\begin{array}{l}\alpha \\
\alpha \\
\end{array}$ & 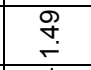 & 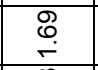 & ְֶ. & 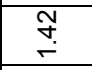 & $\stackrel{ }{\circ}$ & $\begin{array}{l}\bar{\sigma} \\
\dot{m}\end{array}$ & $\stackrel{\stackrel{\sim}{9}}{=}$ \\
\hline 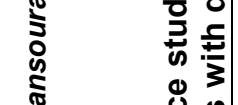 & 总 & 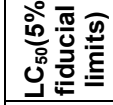 & 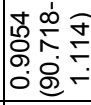 & 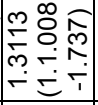 & 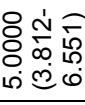 & 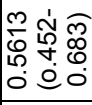 & 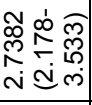 & 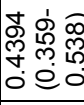 & 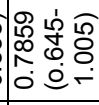 \\
\hline 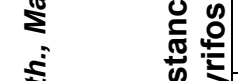 & & $\frac{\circ}{\omega}$ & $\stackrel{\text { L }}{\text { S }}$ & $\stackrel{\mathbb{N}}{N}$ & $\stackrel{\mathbb{N}}{\text { N }}$ & $\stackrel{\text { g }}{\mathrm{i}}$ & ָึ & $\stackrel{\mathscr{O}}{\mathrm{e}}$ & S్ \\
\hline 离 & $\stackrel{\mathscr{\omega}}{=}$ & 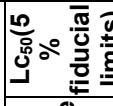 & & $\begin{array}{l}190 \\
08 \\
00 \\
0\end{array}$ & 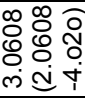 & 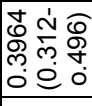 & 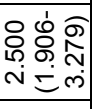 & 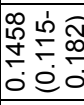 & 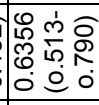 \\
\hline 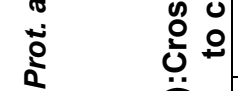 & ס & $\frac{0}{0}$ & 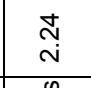 & Ni & 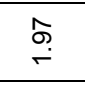 & 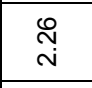 & $\stackrel{\mathbb{N}}{\mathrm{N}}$ & $\begin{array}{l}\stackrel{\leftrightarrow}{0} \\
i \\
\end{array}$ & $\stackrel{\stackrel{\circ}{\infty}}{\stackrel{\infty}{N}}$ \\
\hline 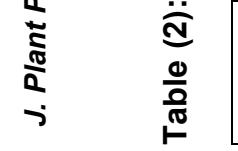 & 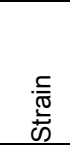 & 苋 & 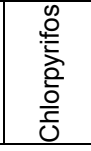 & 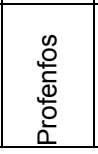 & $\begin{array}{l}\stackrel{\infty}{0} \\
\stackrel{0}{0} \\
\frac{\pi}{\pi} \\
0 \\
\end{array}$ & $\begin{array}{l}\overline{\vec{\varepsilon}} \\
0 \\
\bar{c} \\
\sum \\
\sum\end{array}$ & 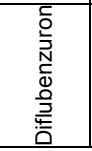 & 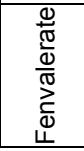 & 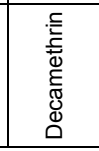 \\
\hline
\end{tabular}

